\title{
Sphere Based Assessment of Psychosocial Support Services at Internally Displaced Person Camps in Maiduguri, Borno State, Nigeria
}

\author{
Pindar SK ${ }^{*}$, Onyencho VC1, Ibrahim AW ${ }^{1}$, Mshelia AA ${ }^{2}$, Placidus $0^{2}$ \\ and Mshelia $\mathrm{AI}^{2}$ \\ ${ }^{1}$ Mental Health Department, University of Maiduguri, Nigeria \\ ${ }^{2}$ Mental Health Department, Federal Neuropsychiatric Hospital, Nigeria
}

*Corresponding author: Pindar SK, Mental Health Department, Faculty of Clinical Science, College of Medical Science, University of Maiduguri, Nigeria, Tel: 234-8020803274; Email: sadiqpin@gmail.com

\section{Research Article \\ Volume 2 Issue 1}

Received Date: May 14, 2018

Published Date: June 15, 2018

DOI: $10.23880 / \mathrm{mhrij}-16000120$

\section{Abstract}

This study examined available psychosocial support services at internally displaced persons camps in Maiduguri, Borno State, Nigeria based on sphere standards and indicators. This is a descriptive, cross-sectional study using multistage sampling technique; cluster sampling technique was used to select nine IDP camps and finally 450 household heads or family representatives were selected through systematic sampling techniques. Families were asked about social services; place of worship 435 (96.6\%), community celebration 436 (96.8\%), funeral services 428 (96.2\%), recreational facilities for children 198 (44\%), and $20(4.4 \%)$ were opportune to participate in relief effort such as construction of mosques, schools, water pumps, sanitation facilities. Only $14.4 \%$ reported family member with symptoms of posttraumatic stress disorder; vivid imagery related to a violent memory, 45 (10\%) families member with a previously diagnosed mental disorder, of which 25 (55.5\%) are still receiving regular medication from Psychiatric hospital and 20 (45.5\%) had abruptly stopped medication. This study revealed that creation of recreational facilities for children is essential and more IDPs should be giving opportunity to participate in relief effort and community development. Also, psychotropic drugs should be made free and available in the camps.

Keywords: Internally Displaced Persons; Nigeria; Sphere Standards; Indicators

Abbreviations: MHPSS: Mental Health and Psychosocial Support; IDPs: Internally Displaced Persons; NEMA: National Emergency Management Agency; SEMA:
State Emergency Management Agency; WHO: World Health Organization. 


\section{Mental Health \& Human Resilience International Journal}

\section{Introduction}

North-eastern part of Nigeria has witnessed one of the worst armed conflicts in recent times. According to International Federation of Red Cross and Red Crescent societies (2000) [1], a crisis disastrous when ten or more people are reported killed, hundred or more people are reported affected, an appeal for international assistance is issue and state of emergency is declared. Out of the 40.8 million displaced from arms conflict and violence worldwide about 2,152,000 was displaced in Nigeria according to Internally Displaced Management Centre [2], over 1.5 million displaced persons are housed in overcrowded camps across the disturbed northern region [3]. Also, the ongoing crisis has generated an estimated 13,000 - 17, 500 deaths, and resulted in massive population displacement due to the fear of insurgents, assaults, destruction of property, and loss of livelihood [4$6]$.

In a humanitarian disaster, about $30-50 \%$ affected people develop signs of psychological distress in varying degrees manifesting as non-specific distress and psychosomatic symptoms rather than a particular syndrome. Rates of mental disorders, especially mild to moderate, are expected to rise [7]. In the months that follow a disaster victims are more likely than non-victims to experience interpersonal, financial, ecological changes and stress. In a study conducted by Onyencho VC, et al. [8] in which the psychosocial needs and services available at the IDP where assessed using HESPER revealed that basic needs such as food, clothing and shelter were grossly inadequate as reported by majority of displaced persons.

Similarly, Irfan M, et al. [9] assessed psychosocial support services for displaced persons in Pakistan based on sphere standards and indicators. The study revealed that funeral services, space for community celebrations, tracing services, psychiatric care and information need significant improvement. There has always been a need for the development of a humanitarian charter to cater for this need, spare project launched in 1997, produced a "Humanitarian Charter" and identified "Minimum Standard" for relief operations in disasters, in the area of water supply and sanitation, nutrition, food aid, shelter and health services. Mental Health and Psychosocial Support (MHPSS) have already been discussed as a standard in the 2004 Sphere Handbook on Mental and Social aspects of Health, covering standards and indicators for the acute emergency phase of a humanitarian $[10,11]$.
Previous studies failed to assess the level of psychosocial support services among IDP in Maiduguri based on sphere standards and indicator, the only accessible study was on the humanitarian emergency settings perceived needs scale [8]. The parameter used by sphere standards and indicators is quite different from the humanitarian emergency settings perceived needs scale in psychosocial support services available among the IDPs. Considering the ongoing humanitarian disaster in the North Eastern Nigeria, this study was conducted to assess the psychosocial needs and services available at the Internal Displaced person's Camp in Maiduguri based on sphere standards and indicators.

\section{Method}

\section{Design and Setting}

This is a descriptive, cross-sectional study conducted at the IDPs camps in Maiduguri, Borno of State Nigeria.

\section{Sampling Techniques}

Multi-stage sampling techniques were employed; cluster sampling technique was used to select 9 internally Displaced Persons (IDPs). Four hundred and fifty household heads or the family representative residing in the camps were selected at an interval of 9 through systematic sampling technique.

\section{Participants}

The minimum sample size was computed using a prevalence of $50 \%$ and $95 \%$ confidence interval with a corresponding critical value (Z) of 1.96 and 0.05 degree of precision. This yielded a minimum sample size of 384 respondents but in order to increase the power, 450 participants were assessed.

\section{Instruments}

Socio-demographic information: Semi structure questionnaire was design to tap information on the demographic and social information of the participants. Also, questionnaire of the Sphere Project (2004) Humanitarian chapter and minimum standards in disaster response questionnaire was administered to assessed information on the available services at the IDPs camps.

\section{Ethical Clearance}

Ethical clearance was sought from both Borno state ministry of health, the ministry coordinates Borno state 


\section{Mental Health \& Human Resilience International Journal}

government activities in various IDPs camps within the state through the State Emergency Management Agency (SEMA); and National Emergency Management Agency (NEMA) an agency that coordinates Federal Government activity within the camps after the protocol was found to be in substantial compliance within the Declaration of Helsinki research on human subjects.

\section{Analysis}

Descriptive statistic was employed for the analysis of the data.

\section{Results}

An average household size of 6.9 persons per family, the average household had 4.5 children. Among the families we surveyed 119 (26.4\%) families did not relocate with them to the IDPs camps. Of these, members of $100(22.2 \%)$ families are still missing out of which 90 (20\%) believes they might still be recue. However only 4 families without missing members were unaware of tracing services; difference in awareness between families with missing members and no missing members was not statically significant $(\mathrm{x} 2=0.4371 ; \mathrm{p}>0.005)$.

Our study revealed that 293 (65.1\%) families had school going children before they left their villages, 444 (98.6\%) families were aware of school facilities in the camp, 349 families reported that their children are using these facilities. There was statistical significant difference between the families with school going children and the families of non-school going children (x2 = 0.002; p < 0.005).

According to the camps administration there were 15 schools present at the selected camps as at the time of this survey established by government, and other nongovernmental organizations. Families were asked about social services; their awareness varied widely for various social services

- $\quad$ Place of worship 436 (96.6\%);

- Community celebration 435 (96.6\%);

- Funeral services 428 (96.2\%);

- Recreational facilities for children 198 (44\%);

- $20(4.4 \%)$ were opportune to participate in relief effort and construction of mosques, schools, water pumps, sanitation facilities.

Of 450 Families 197 (43.7\%) reported that they have been informed about situation in their hometown after arrival through camp administration which comprises of military, national emergency management agency (NEMA), state emergency management agency (SEMA) and non-governmental organizations. Other mode of information dissemination were through place of worship 171 (38\%), through mobile team 40 (8.8\%), none got information through pamphlet.

One hundred and twenty families representing twenty eight percent had orphaned persons or members with disabilities. Social involvement activities are available for $29(6.4 \%)$ of the disabled within the camps. The camp administration also reported the absence of any rehabilitation and recreational facility for the disabled and the absence of database of disabled and orphaned individuals.

On post-traumatic stress disorder, 65 (14.4\%) reported a family member experiencing vivid imagery related to a violent memory, 45 (10\%) families reported a family member with a previous diagnosed mental disorder, of which 25 (55.5\%) are still receiving regular medication from psychiatric hospital, 20 (45.5\%) had abruptly stopped medication due to the displacement. No respondent reported the presence of mental health services in the camps. Averages of 3-4 patients were referred to psychiatric hospital daily from primary health care clinic in the camp.

\section{Discussion}

\section{Key Social Intervention Indicators}

According to our findings, few families were receiving information regarding the situation in their hometown and it was mainly through the administrative staff which comprises the military, NEMA and SEMA. This was in line with a similar study in Pakistan which show that administrative office were the main source of information for the IDP's [9]. This gap needs to be bridged by doing so reduces the spread of rumors and speculation and help create trust between community and relief workers.

The survey showed a positive trend in parents about sending their children to school. Most of the families were aware of school facilities in the camp and majority reported that their children are attending the schools. This findings was contrary with the study of Onyencho VC, et al. [8] among the IDPs who's more than 50\% of the participant's sees inability of their children to attend school as a serious problem. 


\section{Mental Health \& Human Resilience International Journal}

This study showed that only $4.4 \%$ families were offered opportunity to participate in ongoing activities within the camps as opposed to $39 \%$ families in a similar study carried out in IDP's camps in Pakistan [9]. Engaging youths in developing community projects such as constructing schools and participation in community activities help restore sense of efficacy and belongings.

Their awareness varied widely for various social services; there was high awareness for place of worship, community celebration, funeral services among the IDPs while awareness for children recreational facilities was very low because it is totally unavailable. Only 4.4\% IDPs were opportune to participate in relief effort, construction of mosques, schools, water pumps, sanitation facilities, a percentage that is grossly inadequate [9]. Recreational facilities for children, adolescents, and adults are important in terms of showing continuity principle in disaster management. Changes in behavior, attendance in school and psychosocial programmes were found to decrease isolation, violence and aggression in children.

Only few of the families with orphaned and persons with disabled members mentioned any social involvement. The camps does not maintain database of these individuals. However activities for orphaned and disabled should be carefully designed to avoid stigma associated with it. Involvement of community in decision making was minimal evidence of poor consultation in planning the construction of the facilities.

\section{Psychological/Psychiatric Indicators}

Intervention

On psychological/Psychiatric Intervention Indicators, symptoms of post-traumatic stress disorder was experienced by few participants, vivid imagery related to a violent memory was also experienced by few participants. Only $45(10 \%)$ of the families reported having relatives with mental disorder, and only 25 that is $55 \%$ of families with members having mental illness were still receiving regular medication; over $40 \%$ of those receiving medication abruptly stopped medication due to displacement. No respondent report the presence of mental health services in the camps as at the time of this study was conducted. However, recently nongovernmental organizations like World Health Organization "WHO", International Organization of Migration "IOM", etc have supported in managing psychological challenges of the IDPs by financing the psychotropic drugs and admission fee.

\section{References}

1. International Federation of Red Cross and Red Crescent Societies (2000) World disaster report: A focus on public health, Martinus Nijhoff, Dordrecht The Netherlands.

2. (IDMC) (2014) Nigeria: Multiple displacement crises overshadowed by Boko-Haram. International Displacement Monitoring Centre.

3. Humanitarian Bulletin Nigeria issue (2016).

4. Human Rights Watch (2014) World Report: Nigeria. Human Rights Watch, Washington.

5. Amnesty International (2014/2015) Amnesty International Report Nigeria. Amnesty International, Washington.

6. Walker A (2012) What is Boko Haram?. United States Institute of Peace, Washington.

7. WHO (2005) Mental health assistance to the populations affected by Tsunami in Asia, World Health Organization.

8. Onyencho VC, Pindar SK, Ibrahim AW, Mshelia AA, Ogualili P, et al. (2017) Assessment of psychosocial needs among internally displaced persons (IDPS) in Maiduguri based on the humanitarian emergency settings perceived needs scale (HESPER). IOSR Journal of Humanities And Social Science (IOSR-JHSS) 22(7): 17-22.

9. Irfan M, Anwar S, Raza, UA, Qayum M (2011) Assessing the psychosocial support services for displaced persons in Pakistan based on sphere standard and indicators. JPMI 25(2): 118-196.

10. The Sphere Project (2004) Humanitarian charter and minimum standards in disaster response. The Sphere Project, Geneva.

11. IASC (2007) IASC Guidelines on Mental health and psychosocial support in emergency settings. InterAgency Standing Committee. 